\section{Iron Overload Effect on Serum Levels of Glucose, Insulin and HOMA-IR was Ifluenced by the Type of Fat in Female Sprague-Dawley Rats Fed High-Fat-Diets}

\section{Abstract}

Objective: This study was conducted to examine the effect of iron supplementation on serum levels of glucose, insulin and HOMA-IR, and to examine the histological iron deposition in tissue in female Sprague-Dawley rats fed high-fat-diets (HFDs).

Methods: Rats were divided into three main groups: normal fat diet (NFD), high saturated fat diet (HSFD) and high monounsaturated fat diet (HMUSFD). After 6 weeks, rats were sub-divided into three sub-groups for intraperitonial injection of iron (control group, dose1 group (Do1); $15 \mathrm{mg} / \mathrm{kg}$ body weight (BW) and dose 2(Do2); (75 mg/kg BW). Serum glucose and insulin were measured. Also, the histological examination of iron deposition after Perl's Prussian staining was examined.

Results: We indicated that a high dose of iron supplementation decreased total weight gain significantly by 3 folds in rats that were fed the NFD and 2.5 folds in rats that were fed the HMUFD as compared to control sub-groups $(p<0.05)$. Moreover, mean HOMA-IR levels increased significantly in rats received a high dose of iron as compared to controls in the NFD and the HSFD groups $(p<0.05)$ but not in HUSFD. However, liver iron accumulation was increased in HFDs groups compared to NFD.

Conclusion: The findings showed that iron overload complications could be influenced by the degree of saturation of dietary fat. However, the high dose of iron supplementation decreased total weight gain and increased liver weight, accompanied by insulin resistance. It is noteworthy that the diet rich in olive oil could have a protective effect against insulin resistance and adipose tissue iron accumulation.

Keywords: Glucose; HOMA-IR; Hfds; Insulin; Tissue iron deposition
Buthaina Alkhatib ${ }^{1 *}$, Hayder Al-Domi ${ }^{1}$, Maha Shomaf ${ }^{2}$ and Basha'er Abu Irmaileh ${ }^{3}$

1 Department of Nutrition and Food Technology, The University of Jordan, Jordan

2 Department of Histopathology, Faculty of Medicine, The University of Jordan, Jordan

3 Department of Toxicology, The University of Jordan, Jordan

*Corresponding author:

Buthaina Alkhatib

\section{buthaynamk85@yahoo.com}

Ph.D. in Human Nutrition and Dietetics, Department of Nutrition and Food Technology, School of Agriculture, The University of Jordan, Jordan.

Tel: +962 65355000

Citation: Alkhatib B, Al-Domi H, Shomaf M, Abu Irmaileh B (2017) Iron Overload Effect on Serum Levels of Glucose, Insulin and HOMA-IR was Ifluenced by the Type of Fat in Female Sprague-Dawley Rats Fed High-FatDiets. J Clin Nutr Diet Vol. 3 No. 3:23

Received: September 18, 2017; Accepted: September 25, 2017; Published: September 30, 2017

\section{Introduction}

Iron deficiency is the most common cause of anemia worldwide [1]. Globally, iron deficiency anemia affect more than two billion people especially the children due to their higher iron requirements [2]. Moreover, iron deficiency anemia is associated with a decrease in the cellular immune response, mental function, physical activity, and alterations in hormonal regulation [3]. Therefore oral iron supplementation is commonly prescribed for people diagnosed with anemia [1]. Findings of recent reports demonstrated that iron supplementation has complex interactions between diet, the host immune system and the gut micro-biome [4]. The amount of supplemental iron absorbed in the human gastrointestinal tract is low, most of the dose passes into the colon where it becomes available for the pathogenic bacteria [5], which lead to alteration in the composition of the gut microbiota in malnourished children [6].

Oral iron intake could alter gut function and microbial composition through direct induction of reactive oxygen species leading to 
increased cell stress in enterocytes and adversely affects the gut micro-biome, increasing pathogen abundance and causing intestinal inflammation [4]. Iron fortification in rural areas resulted in a significant increase of infection-related mortality, mostly related to malaria and invasive bacterial infections, produced potentially pathogenic gut microbiota profile, upregulation of gut inflammation or increased morbidity due to diarrhea [7]. Dongiovanni and his colleagues [7] found that iron supplementation increased hepatic iron and serum hepcidin fivefold and led to a $40 \%$ increase in fasting glucose in mice. However, iron-supplemented mice had lowered visceral adipose tissue mass, associated with iron accumulation in adipocytes. Moreover, iron-enriched diets up-regulated iron responsive genes and adipokines, favoring insulin resistance [8]. Additionally, Gao and his collaborates [8] found that dietary iron supplementation is associated with increased appetite, thus, serum ferritin was negatively associated with serum leptin in a cohort of patients with metabolic syndrome [9]. However, moderately elevated iron levels are associated with chronic diseases such as atherosclerosis, type 2 diabetes mellitus (T2DM) and premature death [10]. Dysmetabolic iron overload syndrome (DIOS) is characterized by increased ferritin levels, and increased body iron stores in the presence of insulin resistance [8]. Moreover, DIOS with normal or mildly elevated transferrin saturation was observed in approximately a one-third of patients with metabolic syndrome or nonalcoholic fatty liver disease [11].

Iron overload can affect major tissues involved in glucose and lipid metabolism, as well as, organs affected by chronic diabetic complications [12]. Epidemiological studies showed an association between iron stores and the development of metabolic syndrome [13]. Zheng and colleagues [13] noted that liver iron is increased in people with T2DM and insulin resistance [14]. Moreover, increased body iron stores were significantly associated with risk of T2DM [15]. Recently, it was reported that the serum concentration of prohepcidin (a precursor of the mature hepcidin) was significantly higher in males with impaired glucose tolerance, or T2DM than in those with normal glucose tolerance [16].

In liver, iron overload can disrupt insulin inhibition of hepatic glucose production, which together with reduced hepatic extraction of insulin leads to peripheral hyperinsulinemia [17]. Moreover, an iron-enriched diet leads to iron accumulation and insulin resistance in visceral AT in mice [8].

Adipose tissue also seems to have an active role in the modulation of systemic iron metabolism through the production of adipokines, which, interacts with iron metabolism; which suggests that iron overload could contribute to obesity associated AT dysfunction [18]. As such, iron overload could disrupt insulin activity in muscle possibly by activation of stress pathways with generation of ROS, which, lead to the hydroxylation of phenylalanine residues of insulin, and therefore, promotes insulin resistance [19]. Therefore, the objective of this study was to examine the effect of different doses of iron supplementation on serum levels of glucose, insulin and HOMA-IR, and to examine the histological iron deposition in tissue in female Sprague-Dawley rats fed highfat-diets.

\section{Materials and Methods}

\section{Preparation of diets and diets formulation}

A standard American Institute of Nutrition (AIN) diet was used [20]. The modified formulation of AIN-93M diet that replaces casein with egg white solids (AIN-93M-EGG) as a protein source was used [20] as shown in (Table 1). Furthermore, higher amount of tert-butylhydroquinone (TBHQ) was added to high fat diet (HFD) due to their high fat contents and their increased susceptibility to oxidation ( $2 \mathrm{mg}$ for each $10 \mathrm{~g}$ fat) [21]. The estimated minimal nutrient composition for normal fat diet (NFD) group was 14.7 $\%$ protein (egg white), $75.8 \%$ carbohydrates (cornstarch and sucrose) and $9.45 \%$ fat (soybean oil); for high monounsaturated fat diet (HMUFD) was $14.7 \%$ protein (egg white), $45 \%$ fat (35.6\% olive oil with $9.4 \%$ of fat soybean oil), $40.5 \%$ carbohydrates (sucrose and cornstarch) [22] and for high saturated fat diet (HSFD) was $14.7 \%$ protein (egg white), $45 \%$ fat (35.6\% butter milk fat, non-hydrogenated) with $9.4 \%$ of fat soybean oil), $40.5 \%$ carbohydrates (sucrose and cornstarch) [23]. Total calories for all diets were $3.81 \mathrm{kcal} / \mathrm{g}$.

Animals: Eight weeks Sprague-Dawley female rats (54 rats, average weight 105-154 g) were obtained from Jordan University of Science and Technology (JUST), Jordan. Rats were kept at the Animal Unit, School of Agriculture, the University of Jordan, Jordan. Each rat was housed in a single metabolically-ventilated plastic cage (North Kent Plastic Cages, Ltd, Dartford, UK) with a stainless steel wire mesh floor and front. A tray was placed under each cage to collect feces and food spillage. Diet was provided in glass cups and water in glass drinking bottles. Rats were kept under controlled temperature $(22 \pm 2 \circ \mathrm{C})$ and maintained at a 12:12 hours light: dark cycles with free access to water and standard laboratory chow diet for one week of acclimatization [24]. This study was carried out in strict accordance with the recommendations in the Guide for the Care and Use of Laboratory Animals of the National Institutes of Health. The protocol was approved by the Committee on the Ethics of Animal Experiments of The University of Jordan (Permit Number: 27-2956).

Iron supplementation: Iron sucrose injection (VenoferlVifor International Inc., St. Gallen, Switzerland) was used. Each $\mathrm{ml}$ of Vanofer contains $20 \mathrm{mg}$ elemental iron as iron sucrose in water for injection. Each dose of iron was calculated and prepared up to possible volume depended on rat weight before each injection using insulin syringe $(1 \mathrm{~mL})$ [25].

Experimental design: Rats were randomly divided into three main dietary groups: group (1) rats were fed normal fat diet (NFD) $(n=18)$, group (2) rats were fed the high saturated fat diet (HSFD) $(n=18)$ and group (3) rats were fed the high monounsaturated fat diet (HMUSFD) $(n=18)$. All rats were fed ad libitum for 10 weeks. Animals were weighed weekly during the duration of the experiment and three times per week before each injection of iron dose in the last 4 weeks of the experiment. Consumption of diets was measured daily by comparing differences in weight between the amount of food offered and left. After 6 weeks of feeding different diets, rats were sub-divided into three subgroups (control group, dose1 group and dose2 group; $n=6$ ) for the second stage of study ( 4 weeks) with two doses of iron 
supplementation. Rats were kept on their respective diet. Iron was supplemented by intraperitonial injections as two doses of iron sucrose: dose1 (Do1); $15 \mathrm{mg} / \mathrm{kg}$ body weight (BW) and dose 2(Do2); ( $75 \mathrm{mg} / \mathrm{kg} \mathrm{BW),} \mathrm{three} \mathrm{times} \mathrm{per} \mathrm{week,} \mathrm{for} 4$ consecutive weeks [25-27]. In control group, rats received an equivalent volume of sterile saline

After which, rats were sacrificed by chloroform anesthesia, after 12 hours fasting. Blood samples were collected by cardiac puncture and centrifuged immediately. Serum samples were as kept at -20 oC until used [24].

\section{Biochemical analysis}

Glucose analysis: Glucose serum levels were examined by glucose enzymatic reference method with hexokinase using commercial kit (Teco Diagnostics, Lakeview Ave, Anaheim, USA). The absorbance was read against the blank (1000 $\mu \mathrm{l}$ reagent) at $340 \mathrm{~nm}$ with a spectrophotometer (Spectroscan 80D, Biotech Engineering Management Co. Ltd, UK) then values were calculated in $\mathrm{mmol} / \mathrm{L}$.

Serum insulin and HOMA-IR: Serum insulin was measured by commercially available ELISA kit (ELISA Abcam's Rat Insulin Kit, ab100578, Abcam, Cambridge, MA, UK) then the concentrations were calculated in $\mu \mathrm{IU} / \mathrm{ml}$. Insulin resistance was evaluated by the homeostasis model assessment of insulin resistance method (HOMA-IR) described by Matthews et al. (1985). The HOMA-IR index was calculated as follows: (fasting insulin $(\mu \mathrm{lU} / \mathrm{ml}) \times$ fasting glucose $(\mathrm{nmol} / \mathrm{ml})) / 22.5$ [28].
Histological examination: Liver and RPAT samples were fixed in $10 \%$ PBS ( $\mathrm{pH} 7.0-7.2)$ buffered formalin. All tissues were embedded in paraffin after fixation. Histologic staining was performed using Eosin and Perl's Prussian blue method to detect tissue iron deposition $[25,8]$. Tissue samples were examined under light microscope at 200x and 400x (OLYMPUS, USA).

\section{Statistical Analysis}

Statistical analysis was performed using (SPSS for Windows, Rel. 22.0, 2013, Chicago:SPSS Inc). Mean differences were examined using one-way analysis of variance (ANOVA) followed by Tukey's HSD test for mean separation. Shapiro-Wilk test was used to assess normality of distribution. Data are presented as mean \pm SEM and differences between means were considered significant at $p$-value $<0.05$

\section{Results}

Table 2 shows that mean TRPAT weight and total weight gain in NFD-Co sub-group were significantly higher compared to NFDDo1 and NFD-Do2 sub-groups $(p<0.05)$. However, mean final weight and liver weight of NFD-Co sub-group were significantly higher than NFD-Do2 sub-group, but not NFD-Do1 sub-group $(p<0.05)$.

There were significant differences in mean TRPAT weight and total weight gain between the HSFD sub-groups; which were significantly higher in HSFD-Co sub-group as compared to

Table 1 The composition of the normal fat diet (NFD) and the high-fat diets (HFDs).

\begin{tabular}{|c|c|c|c|c|c|c|}
\hline \multirow{3}{*}{$\begin{array}{l}\text { Type of diet } \\
\text { Ingredients }\end{array}$} & \multirow{2}{*}{\multicolumn{2}{|c|}{ NFD (AIN-93M) }} & \multicolumn{4}{|c|}{ High-Fat Diets } \\
\hline & & & \multicolumn{2}{|c|}{ HSFD } & \multicolumn{2}{|c|}{ HMUFD } \\
\hline & Weight (g\kg) & Kcal\% & Weight (g\kg) & Kcal\% & Weight (g\kg) & Kcal\% \\
\hline Cornstarch $^{1}$ & 612.5 & 64.4 & 273.8 & 28.8 & 273.8 & 28.8 \\
\hline Egg white & 140 & 15.0 & 140 & 14.7 & 140 & 15.0 \\
\hline Sucrose & 100 & 10.5 & 100 & 10.5 & 100 & 10.5 \\
\hline Soybean oil ${ }^{2}$ & 40 & 9.5 & 40 & 9.5 & 40 & 9.5 \\
\hline Olive oil & - & - & - & - & 150.5 & 35.6 \\
\hline Butter ${ }^{3}$ & - & - & 150.5 & 35.6 & - & - \\
\hline Fiber ( $\alpha$-cellulose) & 50 & - & 50 & - & 50 & - \\
\hline Mineral mix & 35 & - & 35 & - & 35 & - \\
\hline Vitamin mix & 10 & 1.05 & 10 & 1.05 & 10 & 1.05 \\
\hline Biotin premix ${ }^{4}$ & 10 & - & 10 & - & 10 & - \\
\hline Choline & 2.5 & - & 2.5 & - & 2.5 & - \\
\hline TBHQ $^{5}$ & $8 \mathrm{mg}$ & - & $38.2 \mathrm{mg}$ & - & $38.2 \mathrm{mg}$ & - \\
\hline Total weight (g) & 1000 & - & 812.0 & - & 812.0 & - \\
\hline Total energy (Kcal) & - & 3812 & - & 3812 & - & 3812 \\
\hline
\end{tabular}

NFD): the normal fat diet, (HSFD): the high saturated fat diet, (HMUFD): the high monounsaturated fat diet.

1. The amount of cornstarch include $155 \mathrm{~g}$ extra of cornstarch used as substitution for the dexterinized cornstarch because it is used for facilitating pelleting while no pelleting was done here.

2. Crude refine soybean oil without added vitamins was used in the current study.

3. Butter melted on a water path.

4. Biotin premix was made by mixing $130 \mathrm{mg}$ of biotin with $999.87 \mathrm{~g}$ of cornstarch (Reeves, 1996).

5. The amount of Tert-butylhydroquinone (TBHQ) was added according to the amount of fat ( $2 \mathrm{mg}$ for each $10 \mathrm{~g}$ fat. 
Table 2 The effect of the HFDs in combination with iron supplementation on mean liver weight, TRPAT weight, final weight and total weight gain for 4 weeks.

\begin{tabular}{|c|c|c|c|c|c|c|}
\hline Variables* & Sub-groups (n) & $\begin{array}{l}\text { Weights before iron } \\
\text { supplementation (g) }\end{array}$ & $\begin{array}{c}\text { Liver } \\
\text { Weight (g) }\end{array}$ & $\begin{array}{l}\text { TRPAT } \\
\text { wt. (g) }\end{array}$ & $\begin{array}{l}\text { Final Weight } \\
\text { (g) }\end{array}$ & $\begin{array}{l}\text { Total Weight } \\
\text { Gain (g) }\end{array}$ \\
\hline \multirow{3}{*}{ NFD } & NFD-Co (8) & $203.0 \pm 6.80^{\mathrm{a}}$ & $5.95 \pm 0.2^{\mathrm{a}}$ & $3.00 \pm 0.36^{c}$ & $219.4 \pm 8.3^{b}$ & $12.0 \pm 1.6^{c}$ \\
\hline & NFD-Do1 (8) & $203.0 \pm 4.37^{a}$ & $6.48 \pm 0.2^{\mathrm{ab}}$ & $2.28 \pm 0.20^{b}$ & $206.3 \pm 2.2^{\mathrm{ab}}$ & $0.6 \pm 2.4^{b}$ \\
\hline & NFD-Do2 (8) & $203.1 \pm 3.15^{\mathrm{a}}$ & $6.95 \pm 0.3^{b}$ & $0.98 \pm 0.08^{a}$ & $202.3 \pm 4.0^{\mathrm{a}}$ & $-6.8 \pm 2.2^{\mathrm{a}}$ \\
\hline \multirow{3}{*}{ HSFD } & HSFD-Co (7) & $200.0 \pm 8.9^{a}$ & $6.58 \pm 0.5^{\mathrm{a}}$ & $3.84 \pm 0.40^{c}$ & $210.6 \pm 12.6^{a}$ & $10.2 \pm 3.5^{\mathrm{a}}$ \\
\hline & HSFD-Do1 (7) & $201.1 \pm 11.3^{a}$ & $7.27 \pm 0.5^{a}$ & $2.41 \pm 0.23^{b}$ & $214.9 \pm 8.2^{\mathrm{a}}$ & $9.2 \pm 2.3^{\mathrm{a}}$ \\
\hline & HSFD-Do2 (7) & $200.0 \pm 8.4^{a}$ & $7.55 \pm 0.4^{b}$ & $1.93 \pm 0.23^{a}$ & $206.8 \pm 8.7^{a}$ & $6.9 \pm 6.0^{b}$ \\
\hline \multirow{3}{*}{ HMUFD } & HMUFD-Co (7) & $206.3 \pm 8.9^{a}$ & $7.57 \pm 0.3^{b}$ & $3.88 \pm 0.3^{b}$ & $230.14 \pm 6.6^{a}$ & $23.0 \pm 5.7^{b}$ \\
\hline & HMUFD-Do (8) & $207.3 \pm 6.3^{a}$ & $8.19 \pm 0.4^{\mathrm{a}}$ & $2.74 \pm 0.2^{a}$ & $225.63 \pm 5.0^{a}$ & $19.2 \pm 1.9^{b}$ \\
\hline & HMUFD-Do2 (7) & $207.1 \pm 7.8^{a}$ & $8.53 \pm 0.3^{a}$ & $2.41 \pm 0.3^{a}$ & $219.57 \pm 8.4^{a}$ & $9.3 \pm 2.7^{a}$ \\
\hline
\end{tabular}

*Data are presented as mean \pm SEM, and is significant at $p<0.05$. Means within the same column with different superscript letters are significantly different.

NFD: normal fat diet; HSFD: high saturated fat diet; HMUFD: high monounsaturated fat diet; TRPAT wt.: total retroperitoneal adipose tissue weight; Co: control sub-group without iron supplementation; Do1: iron supplementation dose1 (15 mg/kg); Do2: iron supplementation dose2 (75 mg/kg).

HSFD-Do1 and HSFD-Do2 sub-groups ( $p<0.05)$. Moreover, mean TRPAT weight in HSFD-Do1 sub-group was significantly higher than HSFD-Do2 sub-group and mean total weight gain in HSFDDo2 sub-group was significantly lower than HSFD-Do1 subgroups $(p<0.05)$. Mean liver weight in HMUFD-Co sub-group was significantly lower than HMUFD-Do1 and HMUFD-Do2 sub-groups, while mean TRPAT weight in HMUFD-Co sub-group was significantly higher than HMUFD-Do1 and HMUFD-Do2 sub-groups $(p<0.05)$. Furthermore, mean total weight gain in HMUFD-Do2 sub-group was significantly lower than HMUFD-Co and HMUFD-Do1 sub-groups $(p<0.05)$.

Table 3 shows that mean FBG in dose-2 sub-groups in the NFD and the HSFD was increased significantly as compared to the control sub-group, while HOMA-IR levels were significantly increased as compared to the control group in the HSFD and compared to dose-1 in the NFD group. However, in rats that were fed the HMUFD, mean HOMA-IR levels were significantly decreased compared to control and dose- 1 sub-groups $(p<0.05)$.

Furthermore, iron accumulations were increased in liver at different doses of iron supplementation in the HFDs groups as compared to controls and the NFD groups (Figure 1). In contrast, rats that were fed HSFD and NFD accompanied by the higher dose of iron supplementation recorded the highest iron accumulation in RPAT as compared to HMUFD-Do2 (Figure 2).

\section{Discussion}

Obesity is a state of chronic subclinical inflammation [29], leading to anemia of chronic disease [30]. Evidence indicated that iron overload leads to adipose tissue and endocrine dysfunction; this could affect adipokines secretion and $/ o r$ interupt insulin signals pathways leading to obesity-related diseases [31]. It is therefore pivotal to investigate the effect of different types of fat in combination with iron overload, which could provide an opportunity to develop preventative and even therapeutic approaches, to reduce the risk of obesity associated metabolic consequences if present.
The findings of the current study demonstrated that injecting rats with different doses of iron supplementation $(15 \mathrm{mg} / \mathrm{kg}$ body weight and $75 \mathrm{mg} / \mathrm{kg}$ body weight) decreased total weight gain and RPAT weight, accompanied by increasing liver weight regardless of the diet type, compared to controls within group. With reference to the findings of previous researches, this is consistence with the findings of a study conducted on mice fed iron enriched diet, mice gained less weight than controls, accompanied by decreased in visceral adipose tissue mass, and a reduction in the mean size of visceral adipose tissue, by reducing energy intake and body weight gain $[32,8]$.

Moreover, Gabrielsen et al. [8] reported that the effects of iron on adipose tissue mass are mediated by down-regulation of adiponectin release; by which, fat mass was reduced in ironoverloaded mice [31,33]. Hence, adiponectin contributed to increase the rate of fatty acid oxidation through increased adenosine monophosphate activated protein kinase (AMPK) activation and decreased acetyl Co-A carboxylase (ACC) activity $[33,34]$.

Furthermore, Huang et al. [18] showed that mice fed high-fathigh-iron-diet exhibit a shift from glucose to fatty acid oxidation in fuel performance; however, the decrease in glucose oxidation in muscle is accompanied by increase pyruvate/lactate recycling to liver, and increased hepatic glucose output and protect from diet induced obesity [35]. Also, this mechanism has been explained by the modest degree of mitochondrial dysfunction; it relatively contributed to increase the capacity of fatty acid oxidation in mice fed high-fat diets $[35,32]$. Mice fed high-fat diet with excess dietary iron intake, showed an increase in serum glucose and insulin accompanied by greater hepatic fat accumulation, paralleled to alterations in the hepatic gluconeogenesis enzymes and lipid synthesis due to oxidative stress and mitochondrial dysfunction [32].

The increase of iron dose was accompanied by increase in liver weight in the current study; this was explained by the association 
Table 3 The effect of the normal-fat-diet in combination with iron supplementation on mean fasting blood glucose, fasting insulin and HOMA-IR levels.

\begin{tabular}{|c|c|c|c|c|}
\hline Variables* & Sub-groups (n) & $\begin{array}{c}\text { FBG } \\
(\mathrm{mmol} / \mathrm{L})\end{array}$ & $\begin{array}{c}\text { Fasting } \\
\text { Insulin }(\mu \mathrm{lU} / \mathrm{ml})\end{array}$ & HOMA-IR \\
\hline NFD & $\begin{array}{l}\text { NFD-Co (8) } \\
\text { NFD-Do1(8) } \\
\text { NFD-Do2 (8) }\end{array}$ & $\begin{array}{c}10.09 \pm 0.52^{\mathrm{a}} \\
11.54 \pm 0.42^{\mathrm{ab}} \\
12.62 \pm 0.55^{\mathrm{b}}\end{array}$ & $\begin{array}{l}16.09 \pm 1.86^{\mathrm{a}} \\
13.48 \pm 0.30^{\mathrm{a}} \\
14.16 \pm 0.38^{\mathrm{a}}\end{array}$ & $\begin{array}{l}7.49 \pm 1.52^{\mathrm{ab}} \\
6.95 \pm 0.36^{\mathrm{a}} \\
8.08 \pm 0.54^{\mathrm{b}}\end{array}$ \\
\hline HSFD & $\begin{array}{l}\text { HSFD-Co (7) } \\
\text { HSFD-Do1 (7) } \\
\text { HSFD-Do2 (7) }\end{array}$ & $\begin{array}{l}10.31 \pm 0.29^{a} \\
10.53 \pm 0.42^{a} \\
13.99 \pm 0.57^{b}\end{array}$ & $\begin{array}{l}13.68 \pm 0.35^{a} \\
13.79 \pm 0.17^{a} \\
13.24 \pm 0.15^{a}\end{array}$ & $\begin{array}{l}6.28 \pm 0.22^{\mathrm{a}} \\
6.51 \pm 0.32^{\mathrm{a}} \\
8.19 \pm 0.33^{\mathrm{b}}\end{array}$ \\
\hline HMUFD & $\begin{array}{l}\text { HMUFD-Co (7) } \\
\text { HMUFD-Do1 (8) } \\
\text { HMUFD-Do2 (7) }\end{array}$ & $\begin{array}{l}12.83 \pm 0.41^{b} \\
12.59 \pm 0.25^{b} \\
11.24 \pm 0.39^{a}\end{array}$ & $\begin{array}{l}14.02 \pm 0.48^{a} \\
13.45 \pm 0.18^{a} \\
13.65 \pm 0.15^{a}\end{array}$ & $\begin{array}{l}7.99 \pm 0.40^{b} \\
7.52 \pm 0.17^{b} \\
6.63 \pm 0.29^{a}\end{array}$ \\
\hline
\end{tabular}

*Data are presented as mean \pm SEM, and is significant at $p<0.05$. Means within the same column with different superscript letters are significantly different.

NFD: normal fat diet; HSFD: high saturated fat diet; HMUFD: high monounsaturated fat diet; Co: control sub-group without iron supplementation; Do1: iron supplementation dose1 (15 mg/kg); Do2: iron supplementation dose2 (75 mg/kg); FBG: fasting blood glucose; HOMA-IR: homeostatic model assessment for insulin-resistance.

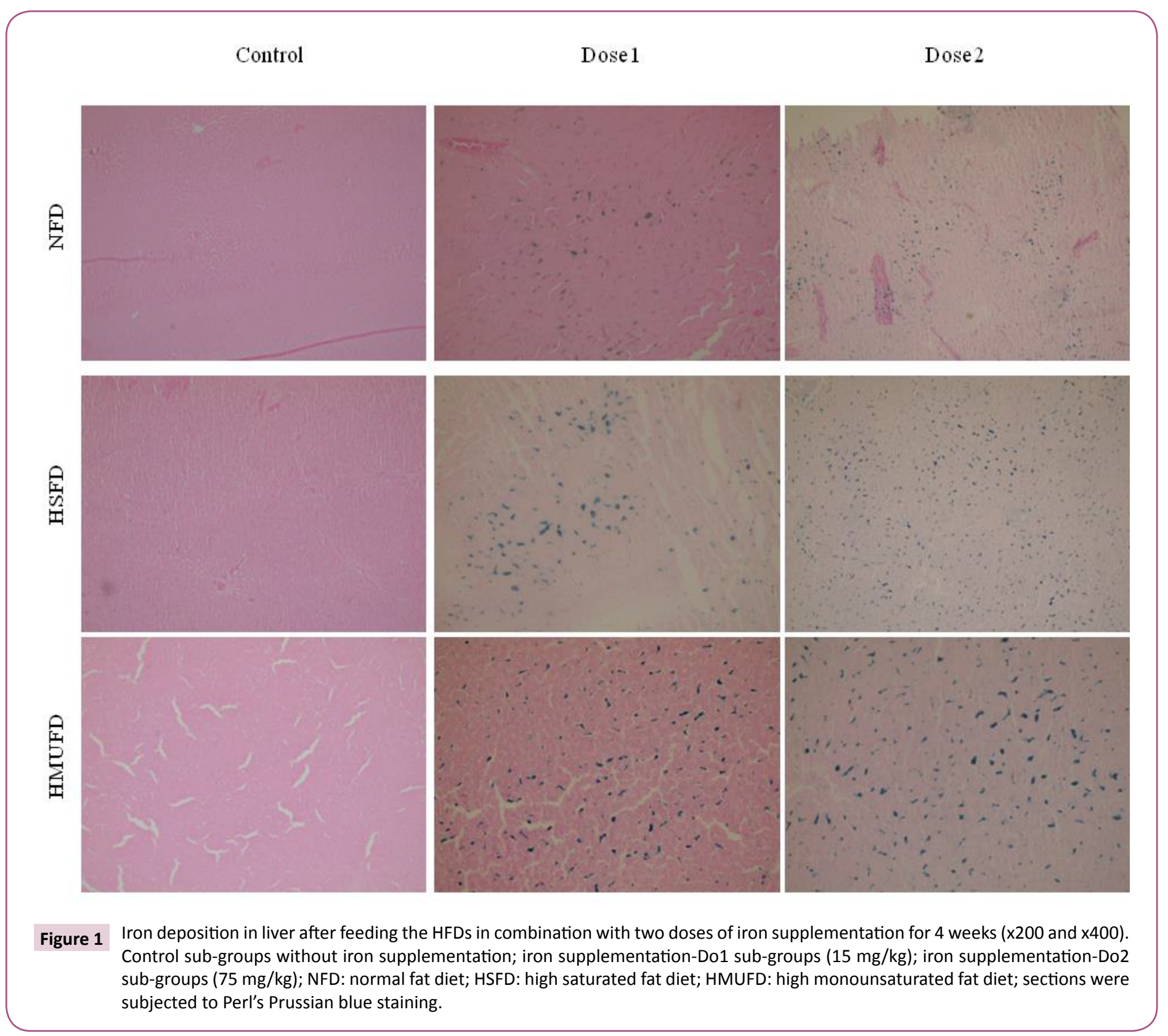




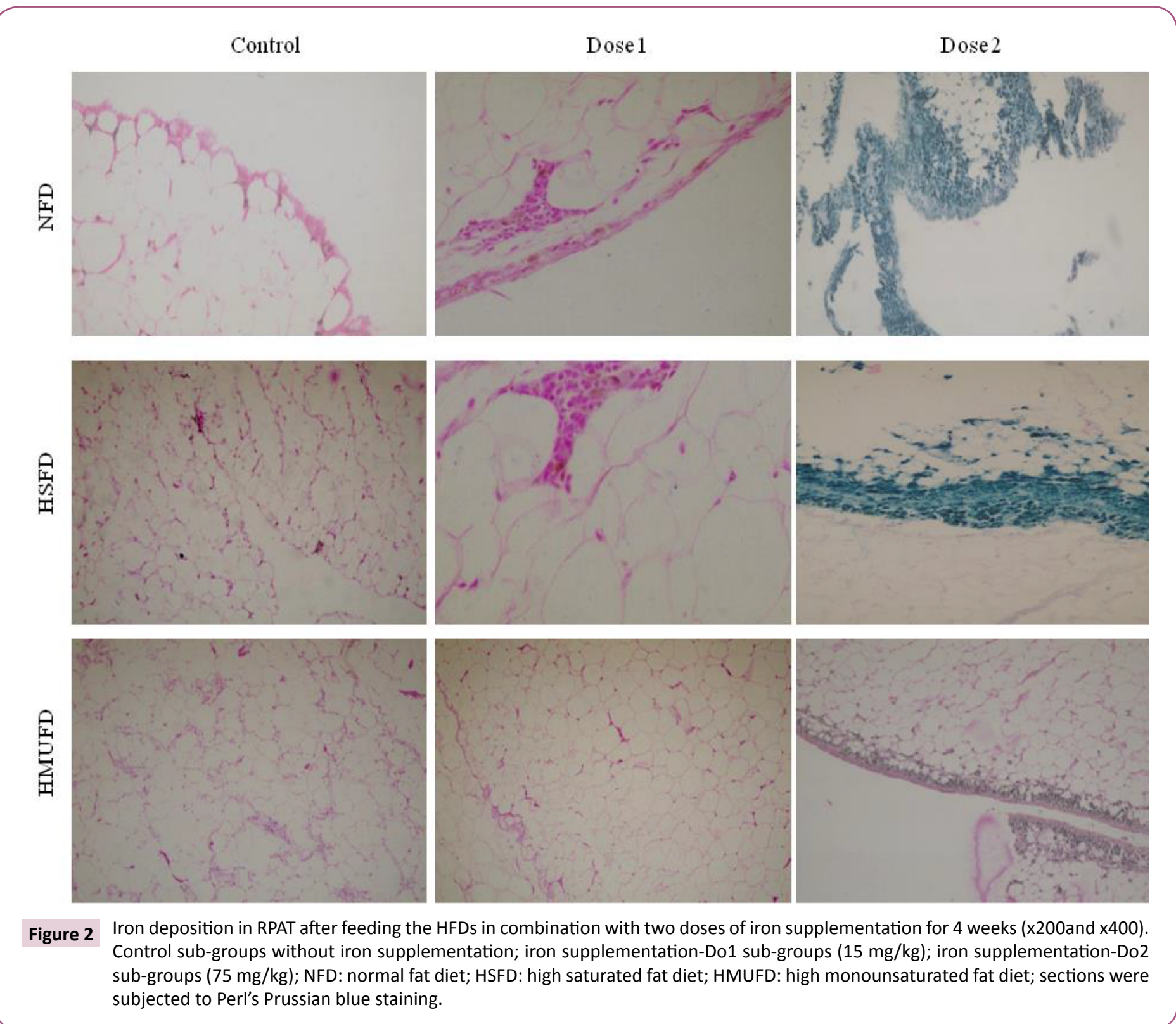

between iron overload and liver fibrosis, which increased liver weight of non-alcoholic fatty liver disease and non-alcoholic steato-hepatitis [12,36]. Furthermore, hepatic fat accumulation accompanied by the iron supplementation could increase liver weight [37], however, in a mice fed the HFD and low-fat diet with dietary iron supplementation, greater hepatic fat was accumulated in all supplemented groups compared to control groups, with respect to the type of diet. These changes were paralleled by alterations in the levels of hepatic gluconeogenesis enzymes, and lipid synthesis [32]. It has been showed that the increase in liver size results from hepatic cellular hypertrophy accompanied by lipid deposition in the liver lobule [38].

The findings of the present study demonstrated that the accumulation of iron in liver after iron overloaded was increased in rat fed HFDs compared to NFD (Figure 1). This was shown in a study on rats by which rats that were fed HFD accumulated more hepatic iron than those fed regular diet, which was associated with development of steatosis [39].
The current study showed that high dose of iron supplementation in the NFD and HSFD decreased insulin sensitivity paralleled to increase iron deposition in RPAT. This result was expected according to what has been reached in many earlier studies to clarify the relationship between the high iron intake or iron overload and insulin insensitivity $[8,31,32,40,41]$. The study of Mendler's et al. [41] demonstrated that patients with unexplained hepatic iron overload were characterized by a mild to moderate iron burden, and that was associated to insulin resistance irrespective of liver damage. In order to explain the association between body iron store and the risk of T2DM [42], Green et al. [39] concluded that transferrin and iron were induced insulin resistance in adipocytes through a mechanism independent of fatty acids [40]. Moreover, Green et al., [39] and Jiang et al. [42] showed that higher iron stores in liver and adipose tissue were associated with increased risk of T2DM in healthy women [40,43].

On the other hand, an epidemiological study showed an association between iron stores and the development of 
metabolic syndrome [13]. Iron overload in liver can disrupt insulin inhibition of hepatic glucose production, which together in conjunction with reduced hepatic extraction of insulin, leads to peripheral hyper-insulinemia [17]. Zheng and his colleagues [13] noticed that liver iron content was increased in people with T2DM and insulin resistance [14], similarly, Bao and colleagues concluded that increased body iron stores were significantly associated with the risk of T2DM [15].

Recently, a study was conducted on mice, by which mice fed the HFD for 7 weeks with dietary iron supplementation, showed that the high iron levels increased blood glucose but decreased high-density lipoprotein cholesterol levels [32]. In mice fed the high iron diet, iron negatively regulated adiponectin transcription and increased insulin resistance, and they demonstrate a causal role for iron as a risk factor for metabolic syndrome [31]. Similarly, iron-enriched diet induces insulin resistance and hypertriglyceridemia [8].

Furthermore, Fargion et al. [35] demonstrated that iron status affects insulin sensitivity by modulating the transcription and membrane affinity of insulin receptor expression in the liver, and influencing insulin-dependent gene expression [36], but Manco et al. [43] was not able to observe a significant difference between insulin sensitivity in patients with and without hepatic siderosis at short period of time, after assessing the intra-hepatic iron in non-alcoholic fatty liver disease (NAFLD) patients [44].

Our results are in line with previous reports in literature which demonstrated the high dose of iron supplementation with the NFD and HSFD groups decreased insulin sensitivity and increased iron accumulation in adipose tissue and major tissue involved in glucose and lipid metabolism $[8,31,44]$ but this was not the case in the HMUFD group by which the diet was rich in olive oil (35.6\%).

Surprisingly, the HMUFD in combination with high dose of iron supplementation protected rats against insulin insensitivity and prevented severe iron accumulation in adipose tissue. This demonstrated that the type of fat that was introduced made an impact that cannot be ignored. It could have a significant effect on the response to the high iron diet or iron supplementation, and consequently affect insulin sensitivity. By reference to the articles that were discussed the role of fat type in insulin resistance, Storlien et al. [44] found that not all types of fat lead to insulin resistance in rats [45]. In addition, Miret et al. [45] demonstrated that olive oil-rich diet did not increase oxidative stress compared to fish oil-rich diet. It has been found that olive oil-rich diet

\section{References}

1 Gisbert JP, Bermejo F, Pajares R, Pérez-Calle JL, Rodríguez $M$, et al (2009) Oral and intravenous iron treatment in inflammatory bowel disease: hematological response and quality of life improvement. Inflam Bow Dis 15: 1485-1491.

2 Zimmermann M, Hurrell RF (2007) Nutritional iron deficiency. Lancet 11: 511-520.

3 Viteri F, Casanuevac E, Tolentinoc CM, Daaz-Francésc J, Berenice- decreases accumulation of triglycerides in liver, accompanied by improving postprandial triglycerides, glucose and glucagon like peptide-1 responses in insulin-resistant subjects [46].

However, most of the conducted studies in human and animals confirmed the olive oil role in protecting against NAFLD, decreasing blood triglycerides, increasing high-density lipoprotein, reducing insulin resistance and hepatic steatosis [47-51]. It has showed that consumption of diets that rich in olive oil has a profound effect on different health outcomes, specially obesity, T2DM and metabolic syndrome [52]. In this line, hydrophilic phenols are the most common natural antioxidants of olive oil, which give it many important biological features, especially antioxidant effect, antiinflammatory, chemo-preventive and anti-cancer [52].

Up to our knowledge, this is the first study that demonstrated the protective role of olive oil in preventing insulin resistance induced by iron overload. Further clinical trials to examine the association between types of dietary fat consumed and deposition in different tissues, and dietary fat assessment on individuals are warranted.

\section{Conclusions}

A high dose of iron supplementation accompanied with HFDs lead to decrease total weight gain and adipose tissue weight significantly, whereas liver weight increased regardless of the diet type. The type of dietary fat that was introduced could have a crucial effect on the response to the high iron diet or iron supplementation, which consequently could enhance insulin sensitivity, tissue iron accumulation and anti-obesity effect.

\section{Author's Contributions}

Buthaina Alkhatib: designing research study, conducting experiment, analyzing data and writing the manuscript.

Hayder Al-Domi: designing research study, conducting experiment and language revision.

Maha Shomaf: microscope techniques, preparation of tissue slides and staining, reading the slide of histopathology

Basha'er Abu Irmaileh: data analysis and preparing reagents.

\section{Acknowledgments}

Authors would like to acknowledge The University of Jordan for funding this study (Deanship of Academic Research, recommendation no. 98/2015-2016). We also would like to thank Hamdi Mango Center for Scientific Research for facilitating their laboratories to undertake the analysis.

Erazoc A (2012) Antenatal iron supplements consumed daily produce oxidative stress in contrast to weekly supplementation in Mexican non-anemic women. Repro Toxi 34: 125- 132.

4 Goldsmith JR, Sartor BR (2014) The role of diet on intestinal microbiota metabolism: downstream impacts on host immune function and health, and therapeutic implications. J Gastro 49: 785-798.

5 Sekirov I, Russell SL, Antunes LC, Finlay BB (2010) Gut microbiota in health and disease. Phys Rev 90: 859-904. 
6 Monira S, Nakamura S, Gotoh K, Watanabe H, Alam NH, et al. (2011) Gut microbiota of healthy and malnourished children in Bangladesh. Fron Micro 2: 228-234.

7 Zimmermann M, Chassard C, Rohner F, N'Goran E, Nindjin C, et al. (2010) The effects of iron fortification on the gut microbiota in african children: a randomized controlled trial in $\mathrm{Co}^{\wedge}$ te d'Ivoire. Amer J Clin Nutr 92: 1406-1415.

8 Dongiovanni P, Ruscica M, Rametta R, Recalcati S, Steffani L, et al. (2013) Dietary iron overload induces visceral adipose tissue insulin resistance. Amer J Path 182: 2254-2263.

9 Gao Y, Li Z, Gabrielsen J, Simcox JA, Lee S, et al. (2015) Adipocyte iron regulates leptin and food intake. J Clin Invest 125: 36-38.

10 Fasola FA, Anetor JI, llesanmi OS (2013) An investigation of the prevalence of iron overload in Nigerian women. African Journal of Medicine and Medical Sciences 42: 231-237.

11 Aigner E, Feldman A, Datz C (2014) Obesity as an emerging risk factor for iron deficiency. Nutr 6: 3587-3600.

12 Fernández-Real JM, Manco M (2014) Effects of iron overload on chronic metabolic diseases. Lanc Diab Endo 2: 513-526.p

13 Park SK, Ryoo JH, Kim MG, Shin JY (2012) Association of serum ferritin and the development of metabolic syndrome in middle-aged Korean men: a 5-year follow-up study. Dia Care 35: 2521-2526.

14 Zheng $X$, Jiang T, Wu H, Zhu D, Wang L, et al. (2011) Hepatic iron stores are increased as assessed by magnetic resonance imaging in a Chinese population with altered glucose homeostasis. American Journal of Clinical Nutri 94: 1012-19.

15 Bao W, Rong Y, Rong S, Liu L (2006) Dietary iron intake, body iron stores, and the risk of type 2 diabetes: a systematic review and metaanalysis. BMC Med 10: 119-127.

16 Derbent A, Simavli, S, Kaygusuz I, Gumus I, Ylmaz S, et al. (2013) Serum hepcidin is associated with parameters of glucose metabolism in women with gestational diabetes mellitus. J Mat, Feta Neo Med 26: 1112-1115.

17 Ferrannini E (2000) Insulin resistance, iron and the liver. Lancet 355: 2181-2182.

18 Ortega FJ, Moreno M, Mercader JM, Moreno-Navarrete JM, FuentesBatllevell N, et al. (2015) Inflammation triggers specific microRNA profiles in human adipocytes and macrophages and in their supernatants. Clin Epi 7: 49.p

19 Huang J, Simcox J, Mitchell TC, Jones D, Cox J, et al. (2013) Iron regulates glucose homeostasis in liver and muscle via AMP-activated protein kinase in mice. FASEB J 27: 2845-2854.p

20 Reeves P (1996) AIN-93 Purified Diets for the Study of Trace Elements Metabolism in Rodents. Trace Elements in Laboratory Rodents, Chapter1: 1-37.

21 Jacob P, de Meneses T, Yamada M, Borges M, Pantaleao L, et al. (2013) Isocaloric intake of a high-fat diet promotes insulin resistance and inflammation in Wistar rats. Cel Biochem Fun J 31: 244-53.

22 Hancock CR, Han DH, Chen M, Terada S, Yasuda T, et al. (2008) High-fat diets cause insulin resistance despite an increase in muscle mitochondria. Proc Nat Acad Sci 105: 7815-7820.p

23 Mahmud I, Al-Domi H (2014) Reversal of obesity and metabolic disorders by exercise in high-fat diet-induced obese $c 57 \mathrm{bl} / 6$ mice. Jor J Agri Sci 10: 426-442.

24 Citelli M, Fonte-Faria T, Nascimento-Silva V, Renovato-Martins M, Silva $R$, Luna $A$ (2015) Obesity promotes alterations in iron recycling. Nutri 7: 335-348.
25 Vu'o'ng-Le B, Khorsi-Cauet H, Villegier AS, Bach V, Gay-Quéheillard J (2011) New rat models of iron sucrose-induced iron overload. Exper Bio Med 236: 790-799.p

26 Dillon R, Momoh I, Francis Y, Cameron L, Harrison HC, et al. (2012) Comparative efficacy of three forms of parenteral iron. J Blo Trans 1-3.

27 Italia K, Colah R, Ghosh K (2015) Experimental animal model to study iron overload and iron chelation and review of other such models. Blo Cel, Mol Dis 55: 194-199.

28 Matthews DR, Hosker JP, Rudenski AS, Naylor BA, Treacher DF, et al. (1985) Homeostasis model assessment: insulin resistance and betacell function from fasting plasma glucose and insulin concentrations in man. Diab 28: 412-419.

29 Albakri A, Al-Domi H, Majdalani K, Nawaiseh H (2014) Adipose tissue remolding and its effect on insulin sensitivity in obese individuals: a critical review. Jor J Agri Sci 10: 215-224.

30 Ghadiri-Anari A, Nazemian N, Vahedian-Ardakani HA (2014) Association of body mass index with hemoglobin concentration and iron parameters in Iranian population. ISRN Hema 3: 525312

31 Gabrielsen JS, Gao Y, Simcox JA, Huang J, Thorup D, et al. (2012) Adipocyte iron regulates adiponectin and insulin sensitivity. J Clin Invest 122: 3529-3540.

32 Choi JS, Koh IU, Lee HJ, Kim WH, Song J (2013) Effects of excess dietary iron and fat on glucose and lipid metabolism. J Nutr Biochem 24: 1634-1644.p

33 Huang J, Gabrielsen JS, Cooksey RC, Luo B, Boros LG, et al. (2007) Increased glucose disposal and AMP-dependent kinase signaling in a mouse model of Hemochromatosis. J Bio Chem 282: 37501-37507.

34 Koves TR, Ussher JR, Noland RC, Slentz D, Mosedale M, et al. (2008) Mitochondrial overload and incomplete fatty acid oxidation contribute to skeletal muscle insulin resistance. Cel Meta 7: 45-56.

35 Huang J, Jones D, Luo B, Sanderson M, Soto J, et al. (2011) Iron overload and diabetes risk: a shift from glucose to fatty acid oxidation and increased hepatic glucose production in a mouse model of hereditary hemochromatosis. Dia 60: 80-87.p

36 Fargion S, Mattioli M, Fracanzani AL, Sampietro M, Tavazz, D, et al. (2005) Hyperferritinemia, iron overload, and multiple metabolic alterations identify patients at risk for nonalcoholic steatohepatitis. Amer J Gastro 96: 2448-2455.

37 Haap M, Machann J, von Friedeburg C, Schick F, Stefan N, et al. (2011) Insulin sensitivity and liver fat: role of iron load. J Clin Endo Meta 96: E958-E961.p

38 Tsuchiya M, Ji C, Kosyk O, Shymonyak S, Melnyk S, et al. (2012) Interstrain differences in liver injury and one-carbon metabolism in alcohol-fed mice. Hepa J 56: 130-139.

39 Dongiovanni P, Lanti C, Gatti S, Rametta R, Recalcati S, et al. (2015) High fat diet subverts hepatocellular iron uptake determining dysmetabolic iron overload. PloS one 10: 0116855.

40 Green A, Basile R, Rumberger JM (2006) Transferrin and iron induce insulin resistance of glucose transport in adipocytes. Meta 55: 1042-1045.

41 Kim KA, Gu W, Lee A, John EH, Kim DH (2012) High fat diet-induced gut microbiota exacerbates inflammation and obesity in mice via the tIr4 signaling pathway. PLOS One 7: e47713.

42 Mendler MH, Turlin B, Moirand R, Jouanolle AM, Sapey T, et al. (1999) Insulin resistance-associated hepatic iron overload. Gastro J 117: 1155-1163.p 
43 Jiang R, Manson JE, Meigs JB, Ma J, Rifai N, et al. (2004) Body iron stores in relation to risk of type 2 diabetes in apparently healthy women. J Amer Med Assoc 291: 711-717.p

44 Manco M, Alisi A, Real JMF, Equitani F, DeVito R, et al. (2011) Early interplay of intra-hepatic iron and insulin resistance in children with non-alcoholic fatty liver disease. J Hepat 55: 647-653.p

45 Storlien LH, Jenkins AB, Chisholm DJ, Pascoe WS, Khouri S, et al. (1991) Influence of dietary fat composition on development of insulin resistance in rats: relationship to muscle triglyceride and $\omega-3$ fatty acids in muscle phospholipid. Diab 40: 280-289.p

46 Miret S, Saiz MP, Mitjavila MT (2003) Effects of fish oil-and olive oilrich diets on iron metabolism and oxidative stress in the rat. Brit J Nutr 89: 11-18.p

47 Alonso A, Martínez-González MA (2004) Olive oil consumption and reduced incidence of hypertension: the SUN study. Lipids 9: 1233-1238.

48 Buettner R, Ascher M, Gäbele E, Hellerbrand C, Kob R, et al. (2013) Olive oil attenuates the cholesterol-induced development of nonalcoholic steato-hepatitis despite increased insulin resistance in a rodent model. Horm Meta Res J 45: 795-801.p
49 Hussein O, Grosovski M, Lasri E, Svalb S, Ravid U, et al. (2007) Monounsaturated fat decreases hepatic lipid content in nonalcoholic fatty liver disease in rats. Worl J Gastro 13: 361-368.

50 El-Kholy TA, Hilal MA, Al-Abbadi HA, Serafi AS, Al-Ghamdi AK, et al. (2014) The effect of extra virgin olive oil and soybean on DNA, cytogenicity and some antioxidant enzymes in rats. Nutr 6: 23762386.p

51 Rodríguez-Villar C, Pérez-Heras A, Mercadé I, Casals E, Ros E. (2004) Comparison of a high-carbohydrate and a high monounsaturated fat, olive oil-rich diet on the susceptibility of LDL to oxidative modification in subjects with Type 2 diabetes mellitus. Dia Med 21: 142-149

52 Perez-Martinez P, Garcia-Rios A, Delgado-Lista J, Pérez-Jiménez F, López-Miranda J (2011) Mediterranean diet rich in olive oil and obesity, metabolic syndrome and diabetes mellitus. Curr Pharm Desi 17: 769-777.p

53 Servili M, Esposto S, Fabiani R, Urbani S, Taticchi A, et al. (2009) Phenolic compounds in olive oil: antioxidant, health and organoleptic activities according to their chemical structure. Inflam-pharma J 17: 76-84. 